\title{
Similitude between 3D cellular patterns in transonic buffet and subsonic stall
}

\author{
Frédéric Plante* Julien Dandois ${ }^{\dagger}$ \\ ONERA, Meudon, France, 92190 \\ Éric Laurendeau \\ Polytechnique Montréal, Montréal, Québec, H3T 1J4, Canada
}

\begin{abstract}
This paper studies the similitude between the 3D cellular patterns which appears in the simulation of transonic buffet and subsonic stall phenomenon using RANS/URANS simulations. These wings are obtained from the extrusion of a 2D airfoil with an added sweep angle and periodic boundary conditions imposed at both ends. This numerical setup allows to study three-dimensional buffet on the simplest configuration possible. Numerical solutions exhibit three-dimensional flows in the form of buffet cells. The latter are convected towards the wing tip when a sweep angle is added leading to the superposition of two frequencies. The first one is independent of the sweep angle and is characteristic of two-dimensional buffet. The second one increases with the sweep angle and is related to the convection of the buffet cells. These cells are reminiscent of the stall cells which are well-known but for low speed flow conditions. Solutions of the URANS equations for infinite swept wings in stall conditions at low speed are computed showing the same convection of the cellular patterns. These results lead us to think the discrepancies between 2D and 3D buffet are caused by the appearance of stall cells, which are the same as buffet cells, and not from a modification of the shock wave boundary layer interaction.
\end{abstract}

\section{Nomenclature}

$a$

$c$

$C_{L}$

$C_{P}$

$f$

$l_{\text {ref }}$

$M$

$M_{2 D}=\frac{U_{2 D}}{a}$

$M_{3 D}=\frac{U_{\infty}^{a}}{a}$

$R e=\frac{\rho U_{\infty}^{a} c}{\mu_{\infty}}$

$\operatorname{Re}_{2 D}=\frac{\rho U_{2 D} l_{\text {ref }}}{\mu_{\infty}}$

$\operatorname{Re}_{3 D}=R e$

St

$t$

$U_{2 D}$

$U_{\infty}$

$\alpha$

$\alpha_{2 D}$

$\alpha_{3 D}$

$\delta$
$=$ Speed of sound

$=$ Chord length

$=$ Lift coefficient

$=$ Pressure coefficient

$=$ Frequency $(\mathrm{Hz})$

$=$ Reference length, chord projected on the plane normal to the leading edge

$=$ Mach number

$=$ Mach number projected on the plane normal to the leading edge

$=$ Freestream Mach number

$=$ Reynolds number

$=$ Reynolds number in the plane normal to the leading edge

$=$ Freestream Reynolds number

$=$ Strouhal number

$=$ time

$=$ Freestream velocity projected on the plane normal to the leading edge

$=$ Freestream velocity

$=$ Incidence $\left(^{\circ}\right)$

$=$ Incidence in the plane normal to the leading edge $\left(^{\circ}\right)$

$=$ Freestream incidence $\left(^{\circ}\right)$

$=$ Sweep angle $\left(^{\circ}\right)$

\footnotetext{
*Ph.D. Student, Department of Aerodynamics, Aeroelasticity and Acoustics, frederic.plante@polymtl.ca

${ }^{\dagger}$ Research Engineer, Department of Aerodynamics, Aeroelasticity and Acoustics, julien.dandois@onera.fr

†Professor, Department of Mechanical Engineering, eric.laurendeau@polymtl.ca, AIAA Member
} 


\section{Introduction}

TRAnsonic buffet has been extensively studied owing to its physical complexity and industrial relevance. This 1 phenomenon results from the interaction between a shock wave and a shock induced separation and causes large chordwise oscillation of the shock wave position. This oscillation induces strong variation of the aerodynamics loads. This phenomenon is self-sustained on fixed wing, but can cause vibration since it can occur at frequencies near the structural ones. Hence, transonic buffet constitutes a boundary of transport aircraft's flight envelope. An extensive review of the literature on the topic of transonic buffet is presented by Giannelis et al. [1].

First, concerning two-dimensional buffet, wind tunnel campaigns have been carried out by numerous researchers. Mc Devitt and Okuno [2] results have been used as a reference for many numerical studies because of the large range of Mach numbers and incidences available for a NACA0012 airfoil. In these cases, the buffet Strouhal number $\left(S t=\frac{f c}{U_{\infty}}\right)$ ranges from 0.06 to 0.09 . Benoit and Legrain [3] investigated the transonic buffet over a RA16SC1 airfoil and obtained similar frequencies. For the past decade, the experimental study of an OAT15A airfoil by Jacquin et al. [4] has been extensively used to validate numerical simulations of transonic buffet owing to the detailed data available. The reported frequencies stay in a range of Strouhal number from 0.062 to 0.073 . More recently, Brion et al. [5] studied the transonic buffet of the OALT15 airfoil, which is designed to promote laminarity. Data are available with a boundary layer tripped at $7 \%$ and $40 \%$ chord as well as free transition. The results with forced transition exhibit a similar behavior as other experiments in turbulent regime with a Strouhal number of 0.07. However, the buffet frequency is larger by an order of magnitude $(S t \approx 1.0)$ for the free transition, for which the transition occurs at the shock foot.

Numerical studies have been carried out to assess the predictive capability of CFD. Works by LeBalleur and Girodoux-Lavigne [6] and Edwards [7] demonstrates the capacity of viscous-inviscid coupling strategies to predict transonic buffet. Accurate solutions have also been obtained using Unsteady Reynolds Averaged Navier-Stokes (URANS) simulations. Thiery et al. [8] studied the effect of the turbulence model and confinement of the wind tunnel wall for the OAT15A airfoil. They show a strong variation of the buffet prediction depending on both parameters. For instance, the Spalart-Allmaras predicted buffet when increasing the incidence angle of $1^{\circ}$ with respect to the experiments with unconfined farfield boundary conditions and reproduced the experiments when considering the tunnel walls. The $k-\omega S S T$ provided solution in fair agreement with the experiments with and without considering tunnel walls, while the baseline $k-\omega$ failed to capture the unsteadiness. Similar observations were made by Goncalves et al. [9] when considering an extensive number of turbulence model for the RA16SC1 airfoil. They also studied the effect of the discretization of the convective fluxes. Their results show that numerical scheme and turbulence model have a strong effect on both buffet onset and amplitude but not on the frequency of the buffet. For instance, the Strouhal number stays in the range 0.073 to 0.078 for a Mach number of 0.642 , a Reynolds number of 4.2 million and an incidence of $5^{\circ}$. The experimental result [3] is a Strouhal number of 0.083. Grossi et al. [10] used Delayed Detached Eddy Simulation DDES [11]. They also reported a strong effect of the turbulence model on buffet simulation. The Edwards-Chandra modification of the Spalart-Allmaras model with compressibility correction was used in their implementation of the DDES. Deck [12] used Detached Eddy Simulation [13] and Zonal Detached Eddy Simulation [14, 15]. As observed by other authors, URANS with the Spalart-Allmaras turbulence model required to increase the incidence to predict unsteadiness. Similar observations were made with DES, but the ZDES predicted the buffet onset at the same incidence as the experiments. To further reduce the impact of modeling, Large Eddy Simulations (LES) have been carried out by Garnier and Deck [16] and Fukushima and Kawai [17]. In summary, URANS simulations are able to reproduce the main features of two-dimensional buffet, but simulation of the turbulent scales might be required to reduce the impact of the turbulence modeling. The turbulent transonic buffet frequencies predicted by CFD are in good agreement with experimental results with Strouhal numbers in the range of 0.06 to 0.09 .

Concerning three-dimensional buffet, most of the experimental studies have been carried out for half wing-body configurations representative of modern transport aircraft. Ross [18] reported a broad spectral content with Strouhal numbers ranging from 0.2 to 0.6. Dandois [19] presented the analysis of two wind tunnel campaigns over 3D half-wing body configurations. The characteristic bump in the pressure spectra is observed at a frequency 4 to 7 times higher than 
the two-dimensional buffet frequency. A superposition of the 3D buffet with the Kelvin-Helmholtz instability is also observed as well as a convection of buffet cells towards the wing tip.

Sartor and Timme [20-23] carried out an extensive study of the RBC12 configuration with (U)RANS and DDES. They simulated unsteady shock motion with various turbulence models, but observed an effect on the buffet onset incidence [23]. They reported Strouhal numbers in the range 0.1 to 0.4 with unsteadiness mostly located on the outer part of the wing. Their results also showed buffet cells. Brunet and Deck [24] carried out a ZDES simulation of the CAT3D model and Ishida et al. [25] presented ZDES results for the NASA CRM. ZDES results on this configuration are analyzed using Dynamic Mode Decomposition (DMD) and Proper Orthogonal Decomposition (POD) by Ohmichi et al. [26]. Using these methods they identified a mode at $S t=\frac{f c}{U_{\text {inf }}}=0.37$ associated with buffet cells and a mode at $S t$ $=0.034$ which is coherent with two-dimensional buffet. This result seems to indicate the superposition of two unsteady phenomena. Iovnovich and Raveh [27] studied infinite swept configurations based on the RA16SC1 airfoil. These configurations are obtained from a swept extrusion of the airfoil and various boundary conditions are used to close the computational domain at the wing tips. In all cases a symmetric boundary condition is imposed at the root. Results showed the occurrence of what they called buffet cells and an effect of the sweep angle on both the amplitude and frequency of transonic buffet. Plante et al. [28] carried out a similar study. In this study, a symmetry plane is imposed at the root of the wing. For this reason the wavelength and amplitude of the cells vary in the spanwise direction. Thus, a very large span is required to get fully developed cells. The present paper is a follow-up of the latter. However, infinite swept configurations are studied. By this we mean that periodicity conditions are imposed to allow the buffet cells to fully develop in the spanwise direction and we impose no spanwise perturbation.

Another phenomenon named stall cells with a pattern very similar to the transonic buffet cells has been observed at low speed in the post-stall regime since the 1970's [29, 30]. Since then, many experimental and numerical studies have been carried out. The cells observed experimentally have an aspect ratio between 1 [31, 32] and 3 chord lengths [33] and their behavior can be steady or unsteady. For instance, Dell' Orso and Amitay [34] observed transition between a single cell and dual stall cell patterns. The observation of steady or unsteady patterns might depend on the visualization technique used and the aspect ratio of the wing [35]. Also, the stall cells seem to only be present for a narrow range of incidence in the post-stall regime [35]. Most of the study agree that the number of cells depends on the span length of the wing [33, 36]. Based on this observation Schewe [36] concludes that the cells are not caused by the effect of the wall in the experiments. Recently Dell'Orso and Amitay [34] carried-out an experimental parametric study of the stall cells on a NACA0015. They observed the transition between a two-dimensional flow separation and fully developed stall cells by increasing the Reynolds number. Broeren and Bragg [37] studied multiple airfoils and concluded that trailing edge separation is necessary to observe stall cells, which were generally steady.

Stall cells have been computed by Bertagnolio et al. [38] in the context of wind turbine design. Kamenetskiy et al. [39] also encountered this type of flow field while investigating the possibility to obtain multiple fully converged solutions of the discretized RANS equations. Manni et al. [40] presented results of stall cells using URANS and DDES simulations. Recent studies point towards an inviscid source for the stall cells. This statement is supported by Elimelech et al. [41] for the reason that the stall cells occur for a wide range of Reynolds numbers. Also, solution using viscous-inviscid coupling methods exhibit structures reminiscent of stall cells [42, 43]. Moreover, Spalart [44] proposed a model based on lifting line theory with which he obtained lift cells. Based on this model, stall cells result from an instability that grows when the lift versus incidence slope is negative. Gross et al. [45] proposed a model based on lifting line theory for the wavelength of the cells with respect to the slope of the $C_{L_{\alpha}}$ curve. Weihs and Katz [46] tried to explain the stall cells based on the Crow instability [47] and Rodriguez and Theofilis [48] linked stall cells formation to the appearance of a global unstable mode.

This paper presents simulations of buffet cells and stall cells for infinite swept wings. This study is novel since the buffet cells have never been studied for infinite swept wings, which is the simplest configuration for which they can occur. Then, at low speed the stall cells are studied on swept wings. Together these results allow to identify similar behaviors between stall cells and buffet cells. The paper will start by presenting the numerical methodology. Numerical solutions of transonic buffet cells and subsonic stall cells will follow and the paper will end with conclusion. 


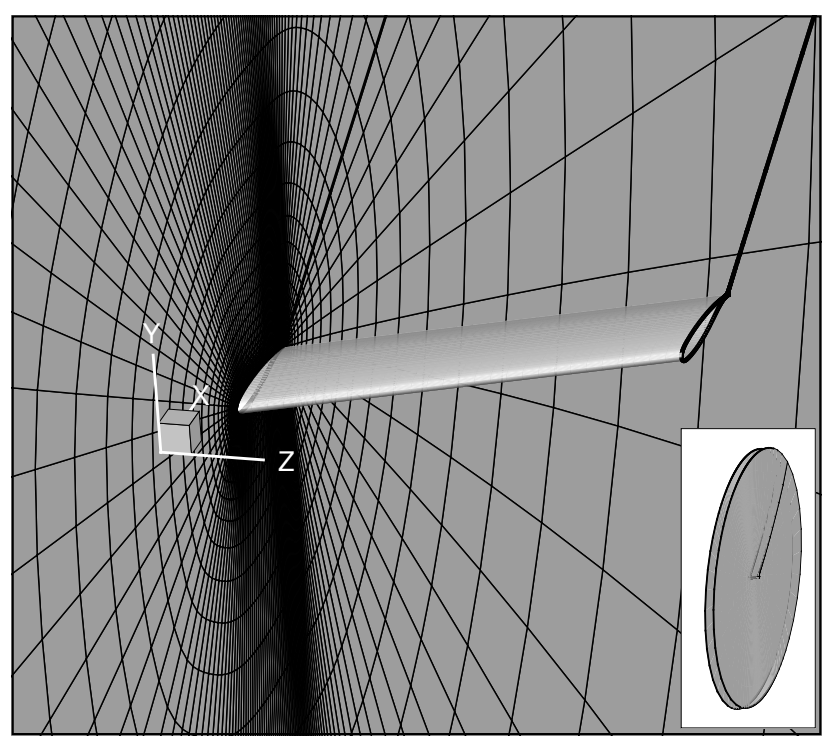

Fig. 1 3D grid

\section{Numerical Method}

Computations are carried out for infinite swept wing configurations obtained from the extrusion of a 2D airfoil. The meshes are generated by extruding a $2 \mathrm{D}$ mesh with a shift in the $\mathrm{x}$-direction to obtain a swept wing. The $\mathrm{x}$-coordinates are modified by a factor $\frac{1}{\cos \delta}$ with $\delta$ the sweep angle to keep the baseline airfoil geometry in the plane normal to the leading edge. Fig. 1 shows the 3D mesh used for transonic buffet with one point over four in all directions. One can observe the angle between the leading edge and the z-axis and the two parallel planes closing the domain at the tips of the wing. The baseline grid for transonic buffet is an O-type mesh of the RA16SC1 airfoil with 640 by 256 cells with a wall spacing of $3 \times 10^{-6}$ chord. In this paper we use a constant spanwise grid spacing of 0.107 chord length and span extensions of 3 and 6 chords are considered. For the subsonic stall conditions, the profile is the FX77W270 airfoil and the mesh is an O-type grid of 512 by 256 cells with a wall spacing of $6 \times 10^{-6}$ and a span of 6 chords. The spanwise grid spacing is 0.107 chord. The span of the wing must be sufficient to allow the development of 3D structures. Moreover, the span might have an impact on the number of cells since the periodic boundary condition forces an integer number of cells in span.

No slip boundary conditions are imposed at the airfoil surface and periodicity is enforced in the spanwise direction. Farfield conditions are imposed on the remaining boundaries. The farfield conditions are modified to maintain the similitude of the cases with respect to values in the plane normal to the leading edge. To do so, the Mach number, Reynolds number and incidence are modified following equation 1

$$
\begin{aligned}
M_{3 D} & =\frac{M_{2 D}}{\cos (\delta)} \\
\alpha_{3 D} & =\arctan \left[\tan \left(\alpha_{2 D}\right) \cos (\delta)\right] \\
\operatorname{Re}_{3 D} & =\frac{\operatorname{Re}_{2 D}}{\cos (\delta)^{2}}
\end{aligned}
$$

The studies presented in this article have used the ONERA-Airbus-SAFRAN elsA software whose development are partially funded by Airbus, Safran, and ONERA which are co-owners of this software. A cell-centered scheme with scalar numerical dissipation is used to discretize the convective fluxes. Convergence is accelerated using local time stepping and geometrical multigrid. Pseudo-time integration is carried out with a LU-SSOR scheme and time accurate solution are computed with a dual time stepping approach. The time step is fixed at $1 \times 10^{-5} s$ for all cases and the one equation Spalart-Allmaras turbulence model is used for closure of the (U)RANS equations. Study of the time step refinement and mesh refinement will be carried out in the final paper. 


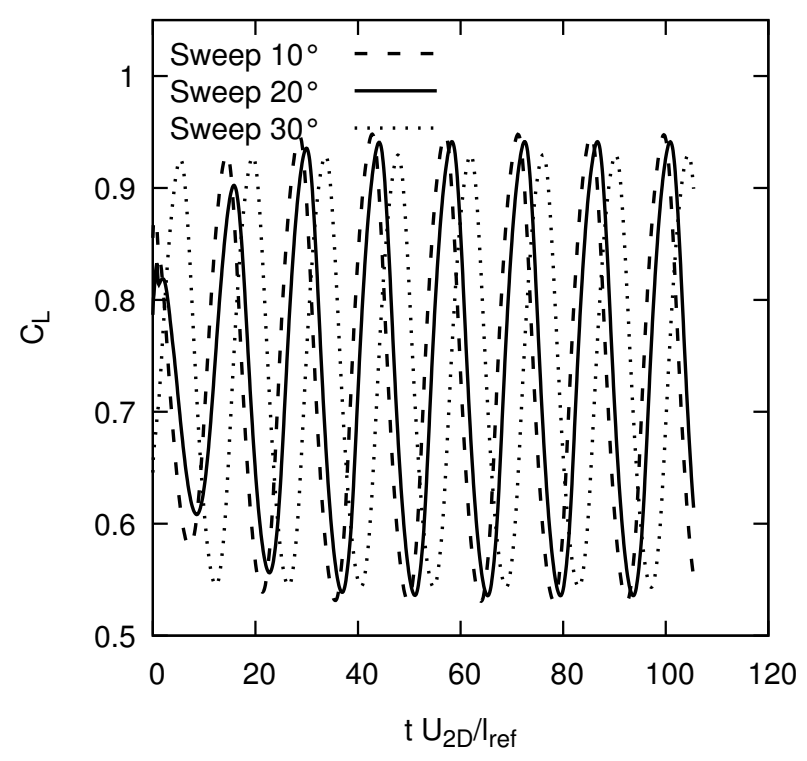

Fig. 2 Lift coefficient for 2.5D cases

\section{Numerical Results}

\section{A. Transonic Buffet}

In this section numerical simulations of the transonic buffet over the RA16SC1 airfoil at a Mach number of 0.732 , an incidence of $3^{\circ}$ and a Reynolds number of 10 million are performed. As mentioned in the previous section, these conditions will be kept constant in the plane normal to the leading edge of the swept wings. The dimensional time step of $1 \times 10^{-5} s$ results in an undimensional time step $\left(\bar{t}=\frac{t U_{2 D}}{l_{\text {ref }}}\right)$ of 0.0105 .

To exclude three-dimensional effects, first computations are performed with a single spanwise cells. Such configuration will be labeled 2.5D cases. Fig. 2 shows the $C_{L}$ coefficients for various sweep angles. One can observe that the cross-flow added by the sweep angle has no effect on the frequency and little effect on the lift amplitude.

Following these results we study three-dimensional wings. Fig. 3 shows the pressure coefficient and the skin friction lines on the suction side of the wings for four sweep angles. We observe a variation of the shockwave position along the span of the wing, forming what has been called buffet cells by Iovnovich and Raveh [27]. For the low sweep angle the skin friction exhibit a shape reminiscent of the stall cells. We also observe that the flow boundary layer is separated in the middle of the cells, but regions of attached flow are present in between them. These cells are convected along the span of the wings.

Fig. 4 and 5 show the global lift and sectional lift coefficients respectively. For a sweep of $10^{\circ}$ and $15^{\circ}$ a large oscillation of the lift coefficient is present. For the latter, the amplitude is in the order of what is observed in $2.5 \mathrm{D}$ computations. For the sweep of 5,20,25 and $30^{\circ}$ the amplitude of the global $C_{L}$ signal is small. One can observe that this trend is not monotone even though buffet cells are present for all these flow conditions and have a similar chorwise amplitude. If only the convection of the buffet cells was present, the global lift of the wing would be constant. Because, an oscillation of the global lift indicates that there is a chordwise variation of the spanwise averaged shock position. Also, we observe that the oscillation of the global forces occurs at a relatively constant frequency. For the sweep of $15^{\circ}$ this corresponds to a Strouhal number of 0.055. This number is close to what is expected of two-dimensional buffet. When looking at the sectional lift coefficients (Fig. 5p, we observe that a large amplitude oscillation of the lift coefficient is present in all cases because the periodic passage of the buffet cells. Also, the frequency of the oscillation increases rapidly with the sweep angle. In the $25^{\circ}$ and $30^{\circ}$ sweep angle cases the amplitude of the oscillation is constant in time, 


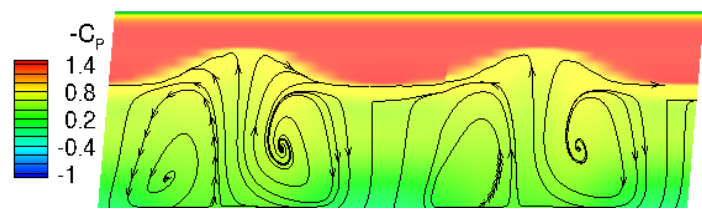

(a) Sweep $5^{\circ}$

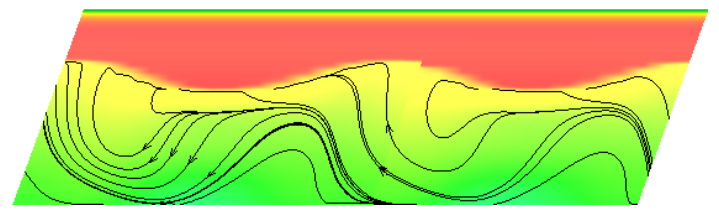

(c) Sweep $20^{\circ}$

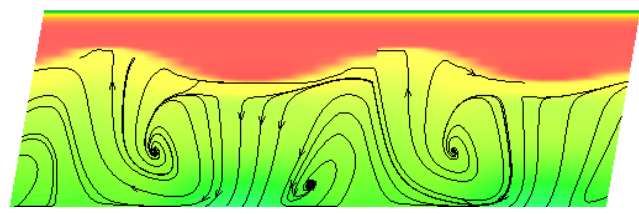

(b) Sweep $10^{\circ}$

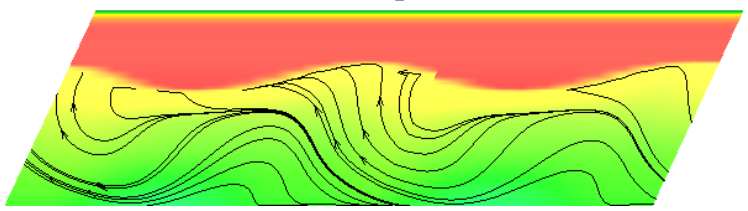

(d) Sweep 25 ${ }^{\circ}$

Fig. 3 Pressure coefficient and skin friction lines for infinite swept wings in buffet conditions

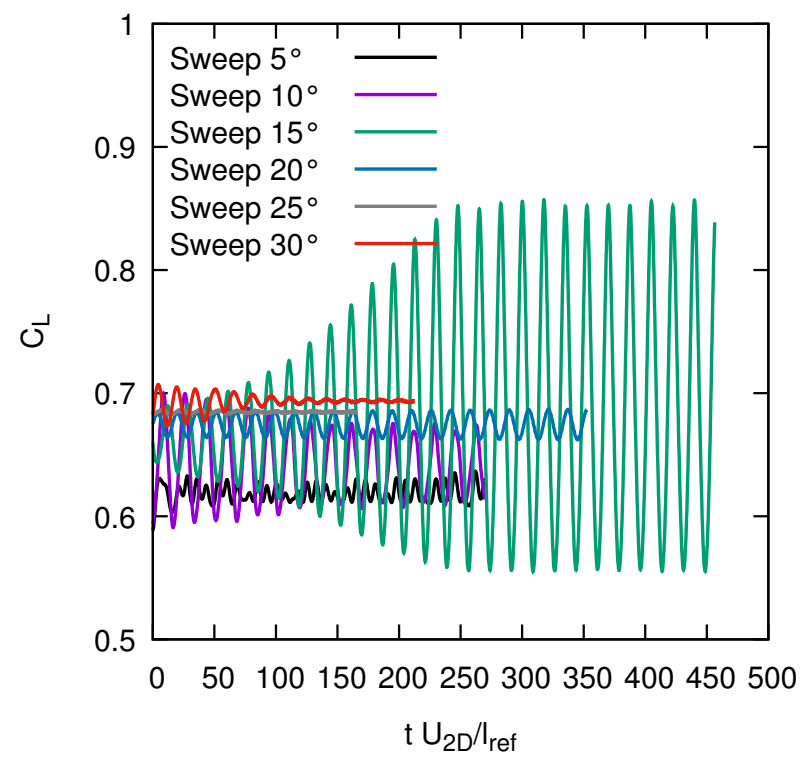

Fig. 4 Global lift coefficient for infinite swept wings in buffet conditions

which is not the case for the other sweep angles. It should be noted that these two sweep angles are the one for which the global lift oscillation almost vanishes.

More insight is obtained by looking at the spectrum of sectional lift coefficients shown in Fig. 6 One can observe that a peak in the spectrum is present near a Strouhal 0.06 for every sweep angles except $15^{\circ}$. However, in this case the two dominant frequencies $(0.055$ and 0.075$)$ are close to this frequency. We note that this frequency is in the range of what is normally observed in two-dimensional buffet. This frequency is also close to the oscillation frequency observed in the global lift coefficients. Other peaks are observed depending on the sweep angle. These frequencies are summarized in Tab. 1. When looking at the movie of the pressure on the skin, we find that these frequencies are related to the convection of the buffet cells. In some case these frequencies are close to harmonics of $S t=0.06$. We also see that these peaks are well defined, in contrary to the bump in the spectra of transonic buffet over aircraft wings in the literature.

Hence, we have the superposition of two phenomena: the classic 2D phenomenon and the convection of buffet cells. The first one occurs at a near constant frequency and the second one increases with the sweep angle. This seems 


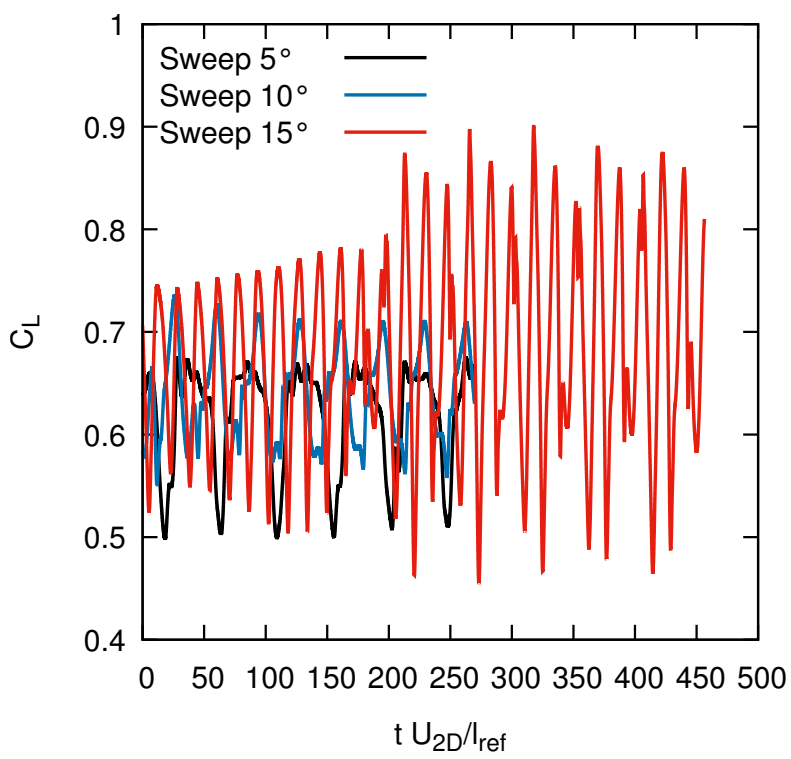

(a)

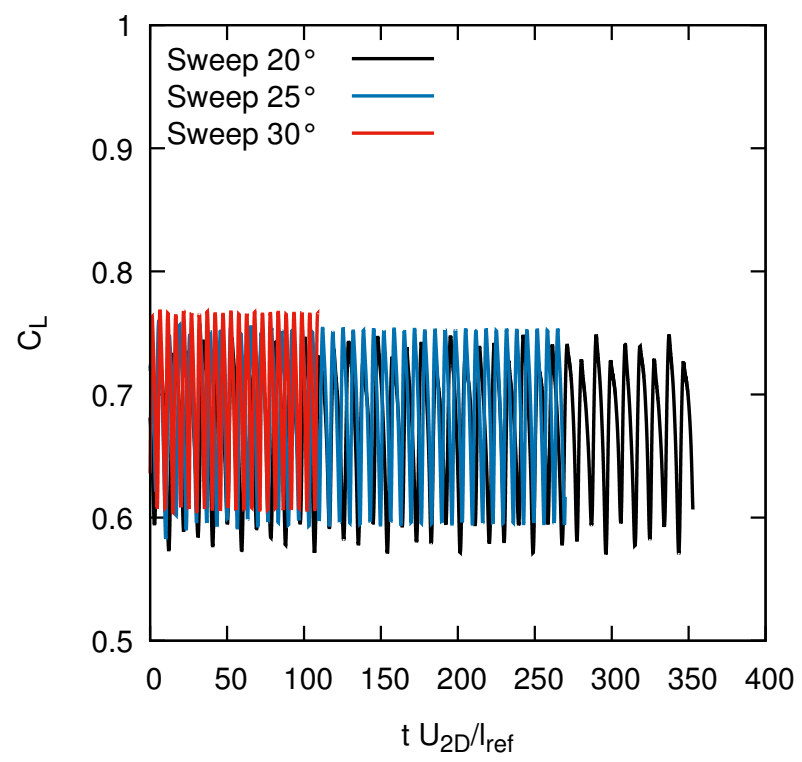

(b)

Fig. 5 Sectional lift coefficient for infinite swept wings in buffet conditions

\begin{tabular}{|c|cccccc|}
\hline Sweep $\left({ }^{\circ}\right)$ & 5 & 10 & 15 & 20 & 25 & 30 \\
\hline Strouhal $\left(S t=\frac{f l_{r e f}}{U_{2 D}}\right)$ & 0.022 & 0.029 & 0.073 & 0.106 & 0.148 & 0.192 \\
Convection speed $\left(\frac{V_{c}}{V_{t}}\right)$ & 0.376 & 0.249 & 0.423 & 0.465 & 0.526 & 0.577 \\
\hline
\end{tabular}

Table 1 Buffet cells convection frequency 


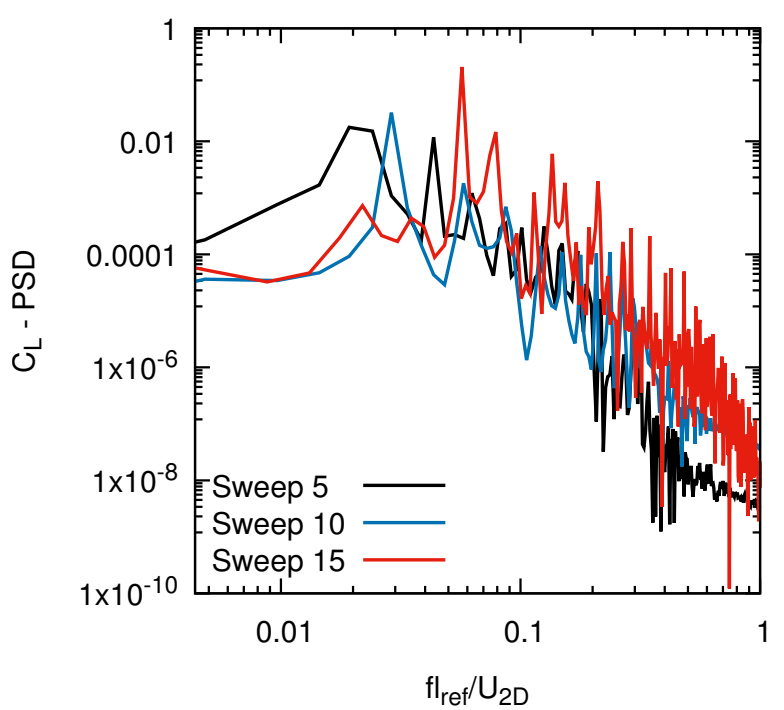

(a)

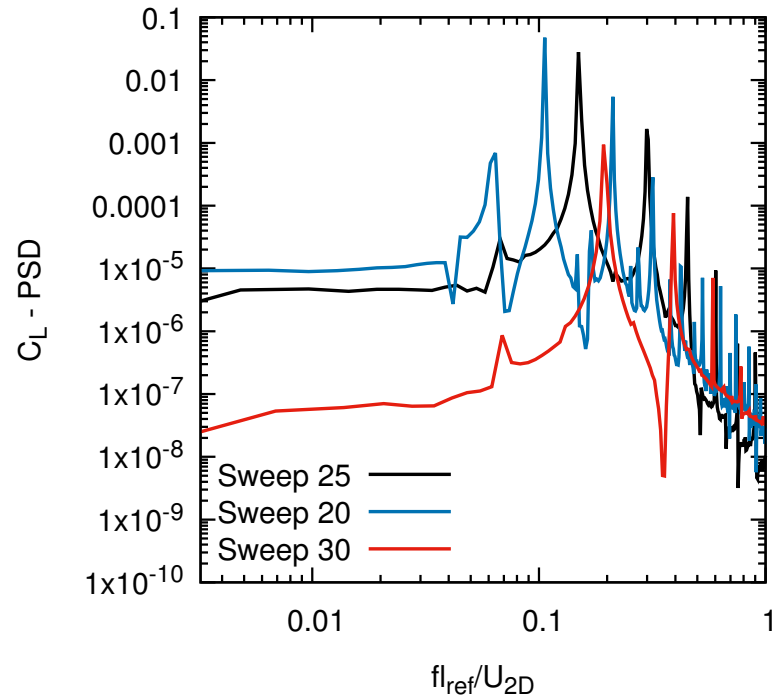

(b)

Fig. 6 Sectional lift coefficients

to indicate that the main reason for the increase of frequency observed for the three-dimensional buffet is caused by the buffet cells phenomenon. In fact, most of the studies of three-dimensional buffet were made on configuration representative of transport aircraft with a leading edge sweep angle in the range $20^{\circ}$ to $30^{\circ}$. For this reason, the convection of buffet cells resulted into a high frequency. The present result shows that for small sweep angle the frequency caused by the convection of buffet cells is lower than the 2D buffet frequency. In contrary to the spectrum of buffet on aircraft wings, our spectrum does not present a broadband bump. Hence, this feature of the aircraft buffet could be related to geometrical parameters like twist, taper and the kink or turbulence, more than to a characteristic of transonic buffet phenomenon. While the source of the transonic buffet has been identified as an interaction between the shock wave and the boundary layer, the buffet cells remains quite unexplained. However, we can notice similitude to the stall cells phenomenon observed in subsonic stall, in particular when looking at the skin friction lines. This phenomenon will be studied in the next section.

\section{Subsonic stall}

Numerical simulations of subsonic stall have been performed on the FX77W270 wind turbine airfoil at a Reynolds number of 741300 and an incidence of $7.5^{\circ}$. The Mach number is set to 0.2 in order to neglect the compressibility effects. This airfoil has been investigated in wind tunnel by Schewe [36]. Fully turbulent simulations are carried out. However, the experiments does not impose the laminar-turbulent transition, which occurs too late to be neglected. Hence, the results of this section have a qualitative value but experimental data in fully turbulent regime would be necessary to allow comparison with RANS computations. Fig. 77 shows the $C_{L_{\alpha}}$ curve for the FX77W270 airfoil in two-dimension. For an incidence of $7.5^{\circ}$, the lift coefficient is 1.06 (1.1 in the wind tunnel tests). In this condition there is a separation near the trailing edge but the flow is not in the stall regime.

First, we look at the case without sweep angle. Fig 8 shows the skin friction lines and pressure coefficient on the suction side of the wing with zero sweep. We clearly see four stall cells with the characteristic mushroom shape reported in the literature. While the flow conditions are different than those of the experiments, the same number of cells is obtained. Hence, the stall cells have a similar aspect ratio. In this case the cells are mostly stationary, but the flow is not converged to a steady state. In URANS, a slow variation of the lift coefficient is observed with a well-marked peak in the spectrum at a Strouhal based on the separation height of 0.21 . This frequency is characteristic of a bluff 


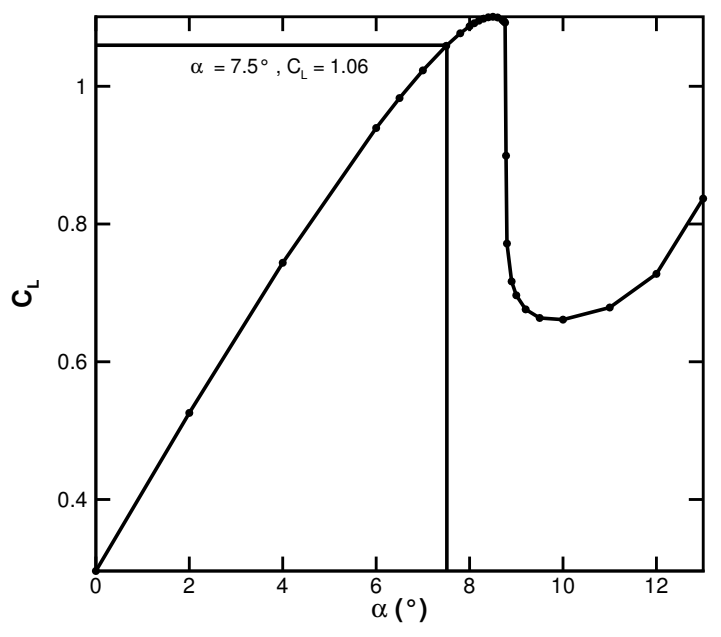

Fig. 7 Lift coefficient versus incidence for the FX77W270 in two-dimension

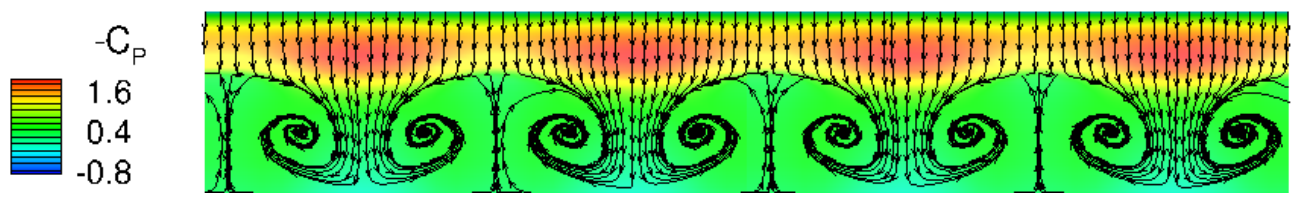

Fig. 8 Pressure coefficient and skin friction lines for the infinite unswept wing in stall conditions (sweep angle $\left.0^{\circ}\right)$

body shedding. One can observe that the topology of the flow is very similar between Fig. 8 and Fig. $3 \mathrm{a}$ This lead us to think that the origin of stall cells and buffet cells is the same.

We now consider an infinite wing swept with an angle of $20^{\circ}$. Fig. 9 shows the skin friction lines and pressure coefficient on the suction side of the wing. We still observe the presence of two structures which are convected in the spanwise direction like in Fig. 3 . Fig. 10 shows the signal of $C_{L}$ on a selected wing section and its power spectral density. We observe a low frequency but high amplitude variation of the sectional $C_{L}$. This lift loss is caused by the passage of a stall cell over the wing section. Here most of the unsteadiness occurs at a frequency related to this convection. Hence, the global $C_{L}$ is almost constant because there is an integer number of cells in span and lift variations in span compensates. We can also observe a very small peak in the high frequency range which can be related to bluff body shedding $\left(1.61 \sin 7.5^{\circ} \approx 0.21\right)$. From these results we can think that the convection of the stall cells is qualitatively similar to the convection of buffet cells.

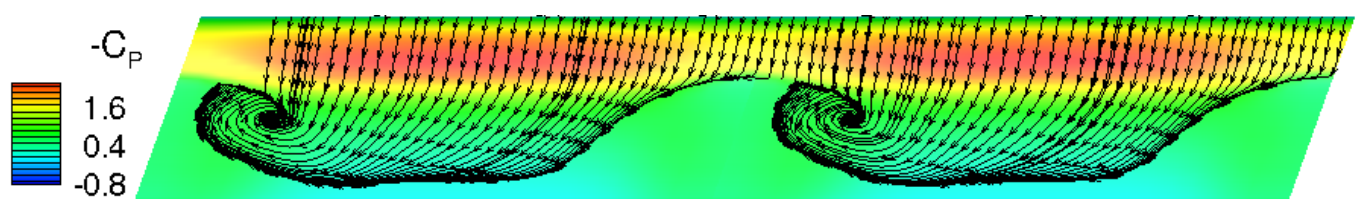

Fig. 9 Pressure coefficient and skin friction lines for the infinite swept wing in stall conditions (sweep angle $\mathbf{2 0}^{\circ}$ ) 


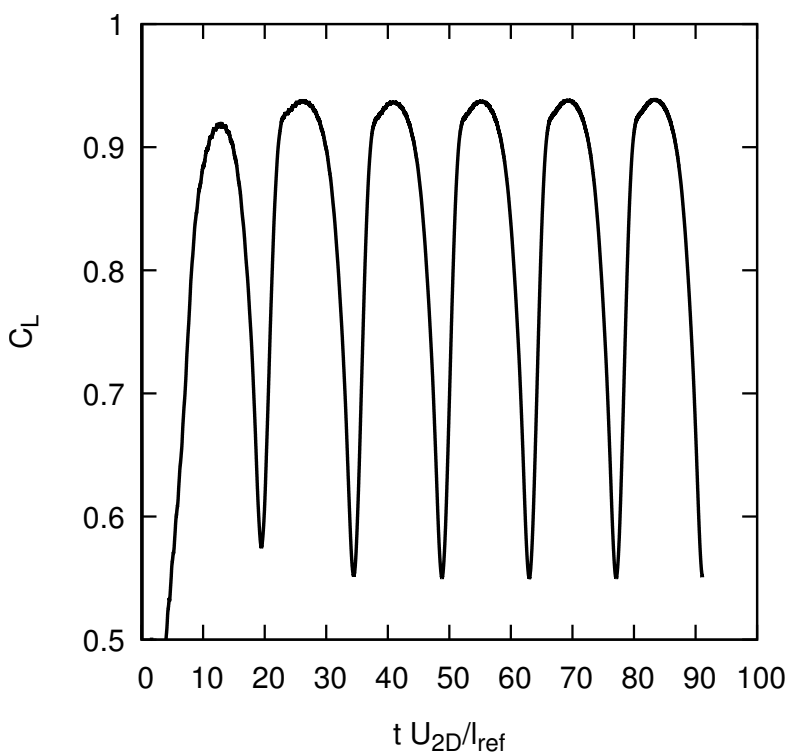

(a) Lift coefficient signal

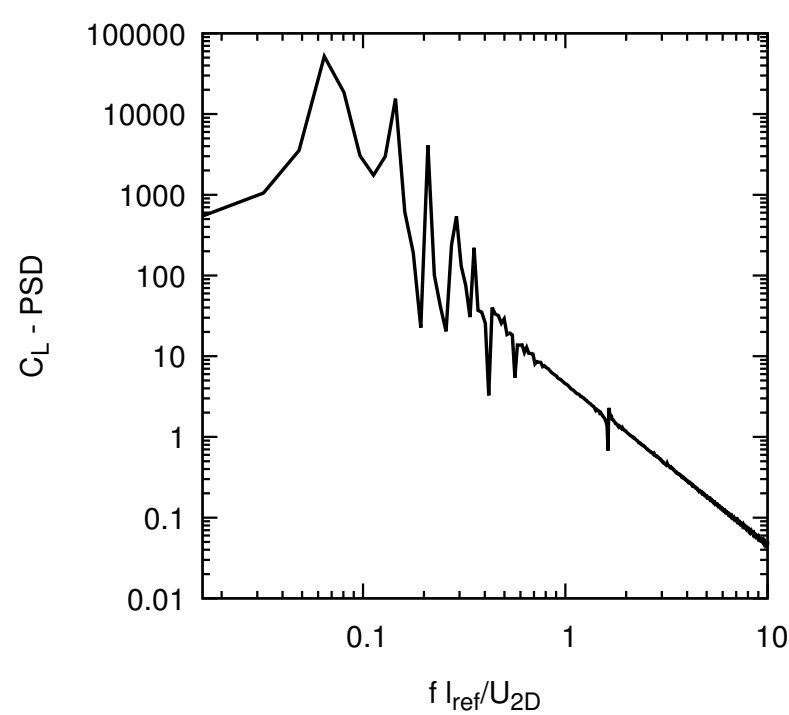

(b) Power spectral density of the lift coefficient

Fig. 10 Sectional lift coefficients for the inifinite swept wing in stall conditions

\section{Conclusion}

Numerical simulations of transonic buffet over infinite swept wings have been performed. Preliminary results show the occurrence of cellular patterns with the characteristic mushroom shape associated to stall cells. These simulations are carried out on infinite swept wings to exclude any effect of three-dimensionality in the boundary conditions or geometry. The 2.5D solutions show that without development of 3D structures, the buffet phenomenon remains very similar to the two-dimensional buffet. The analysis of the frequency content of three-dimensional buffet over infinite swept wings shows the superposition of two phenomena: the 2D buffet which induces variation of the spanwise averaged shock position, and the convection of the buffet cells. The latter results in a varying frequency with respect to the sweep angle. In contrary to the results over aircraft wings, the frequency associated with the convection of the cells is well defined. Hence, the effects responsible for the broadband spectra observed in the experiments are not encountered in infinite swept wings URANS simulations.

Computation of infinite swept wings in subsonic regime with trailing edge separation shows the appearance of stall cells. The structure of those cells compares well with the structure of the buffet cells. Also, when computing a swept wing, the cells are convected towards the wing tip resulting in an unsteady flow very similar to the three-dimensional buffet. In contrary to buffet, the largest part of the unsteadiness is associated with the convection of the stall cells. Hence, without sweep the flow is almost steady. These observations lead us to think that the stall cells and the buffet cells are the same phenomenon. With regards to the literature this means that the buffet cells could be explained by inviscid theories and thus provide a better understanding of the complex phenomenon which is transonic buffet.

For the final paper, time step and grid refinement studies will be presented. An effect of the span will also be presented. The span length of the buffet cells is constrained by the span of the computational domain. Hence, by varying the span we expect to change the number of cells but not the convection speed. This will change the frequency of buffet and provide more insight into the effect of buffet cells. This will also help us develop a model for the convection speed of buffet/stall cells.

For the stall cells at low speed, the effect of the sweep angle will be evaluated for a greater number of sweeps and the trend of the convection speed compared to the one of buffet cells. 


\section{References}

[1] Giannelis, N. F., Vio, G. A., and Levinski, O., "A Review of Recent Developments in the Understanding of Transonic Shock Buffet," Progress in Aerospace Sciences, Vol. 92, 2017, pp. 39-84. doi:10.1016/j.paerosci.2017.05.004.

[2] McDevitt, J. B., and Okuno, A. F., "Static and Dynamic Pressure Measurements on a NACA 0012 Airfoil in the Ames High Reynolds Number Facility,” Technical Report NASA-TP-2485, NASA Ames Research Center, Moffett Field, California, United States, 1985.

[3] Benoit, B., and Legrain, I., "Buffeting Prediction for Transport Aircraft Applications Based on Unsteady Pressure Measurements," AIAA Paper 1987-2356, 1987. doi:10.2514/6.1987-2356.

[4] Jacquin, L., Molton, P., Deck, S., Maury, B., and Soulevant, D., "Experimental Study of Shock Oscillation over a Transonic Supercritical Profile,” AIAA Journal, Vol. 47, No. 9, 2009, pp. 1985-1994. doi:10.2514/1.30190.

[5] Brion, V., Dandois, J., Abart, J.-C., and Paillart, P., "Experimental Analysis of the Shock Dynamics on a Transonic Laminar Airfoil,” Progress in Flight Physics, Vol. 9, 2017, pp. 365-386. doi:10.1051/eucass/2016090365.

[6] Le Balleur, J., and Girodoux-Lavigne, P., "Viscous-Inviscid Strategy and Computation of Transonic Buffet," Symposium Transsonicum III, Springer, Berlin, Heidelberg, 1989, pp. 49-63.

[7] Edwards, J., "Transonic Shock Oscillations Calculated with a New Interactive Boundary Layer Coupling Method,” AIAA Paper 1993-777, 1993. doi:10.2514/6.1993-777.

[8] Thiery, M., and Coustols, E., "Numerical Prediction of Shock Induced Oscillations over a 2D Airfoil: Influence of Turbulence Modelling and Test Section Walls," International Journal of Heat and Fluid Flow, Vol. 27, No. 4, 2006, pp. 661-670. doi:10.1016/j.ijheatfluidflow.2006.02.013.

[9] Goncalves, E., and Houdeville, R., "Turbulence Model and Numerical Scheme Assessment for Buffet Computations," International Journal for Numerical Methods in Fluids, Vol. 46, No. 11, 2004, pp. 1127-1152. doi:10.1002/fld.777.

[10] Grossi, F., Braza, M., and Hoarau, Y., "Prediction of Transonic Buffet by Delayed Detached-Eddy Simulation," AIAA Journal, Vol. 52, No. 10, 2014, pp. 2300-2312. doi:10.2514/1.j052873.

[11] Spalart, P. R., "Detached-Eddy Simulation," Annual Review of Fluid Mechanics, Vol. 41, No. 1, 2009 , pp. $181-202$. doi:10.1146/annurev.fluid.010908.165130.

[12] Deck, S., "Numerical Simulation of Transonic Buffet over a Supercritical Airfoil," AIAA Journal, Vol. 43, No. 7, 2005, pp. 1556-1566. doi:10.2514/1.9885.

[13] Spalart, P. R., Jou, W.-H., Strelets, M., and Allmaras, S. R., "Comments on the Feasibility of LES for Wings, and on a Hybrid RANS/LES Approach,” Advances in DNS/LES, edited by C. Liu, Z. Liu, and L. Sakell, Greyden Press, Columbus, Ohio, United States, 1997, pp. 137-147.

[14] Deck, S., “Zonal-Detached-Eddy Simulation of the Flow Around a High-Lift Configuration,” AIAA Journal, Vol. 43, No. 11, 2005, pp. 2372-2384. doi:10.2514/1.16810.

[15] Deck, S., "Recent Improvements in the Zonal Detached Eddy Simulation (ZDES) Formulation,” Theoretical and Computational Fluid Dynamics, Vol. 26, No. 6, 2012, pp. 523-550. doi:10.1007/s00162-011-0240-z.

[16] Garnier, E., and Deck, S., "Large-Eddy Simulation of Transonic Buffet over a Supercritical Airfoil," Turbulence and Interactions, edited by M. Deville, T.-H. Lê, and P. Sagaut, Springer, Berlin, Heidelberg, 2010, pp. 135-141. doi:10.1007/978-3-642-14139$3 \_16$.

[17] Fukushima, Y., and Kawai, S., "Wall-Modeled Large-Eddy Simulation of Transonic Airfoil Buffet at High Reynolds Number," AIAA Journal, Vol. 56, No. 6, 2018, pp. 1-18. doi:10.2514/1.J056537.

[18] Roos, F., “The Buffeting Pressure Field of a High-Aspect-Ratio Swept Wing," AIAA Paper 1985-1609, 1985. doi:10.2514/6.19851609.

[19] Dandois, J., "Experimental Study of Transonic Buffet Phenomenon on a 3D Swept Wing," Physics of Fluids, Vol. 28, No. 1, 2016, p. 016101. doi:10.1063/1.4937426.

[20] Sartor, F., Sartor, F., Timme, S., and Timme, S., "Mach Number Effects on Buffeting Flow on a Half Wing-Body Configuration," International Journal of Numerical Methods for Heat \& Fluid Flow, Vol. 26, No. 7, 2016, pp. 2066-2080. doi:10.1108/HFF07-2015-0283. 
[21] Timme, S., and Sartor, F., "Passive Control of Transonic Buffet Onset on a Half Wing-Body Configuration," International Forum on Aeroelasticity and Structural Dynamics, Saint Petersbourg, Russia, 2015.

[22] Sartor, F., and Timme, S., "Delayed Detached-Eddy Simulation of Shock Buffet on Half Wing-Body Configuration," AIAA Journal, Vol. 55, No. 4, 2017, pp. 1230-1240. doi:10.2514/1.J055186.

[23] Sartor, F., and Timme, S., "Reynolds-Averaged Navier-Stokes Simulations of Shock Buffet on Half Wing-Body Configuration," AIAA Paper 2015-1939, 2015. doi:10.2514/6.2015-1939.

[24] Brunet, V., and Deck, S., "Zonal-Detached Eddy Simulation of Transonic Buffet on a Civil Aircraft Type Configuration," AIAA Paper 2008-4152, 2008. doi:10.2514/6.2008-4152.

[25] Ishida, T., Hashimoto, A., Ohmichi, Y., Aoyama, T., and Takekawa, K., "Transonic Buffet Simulation over NASA-CRM by Unsteady-FaSTAR Code,” AIAA Paper 2017-0494, 2017. doi:10.2514/6.2017-0494.

[26] Ohmichi, Y., Ishida, T., and Hashimoto, A., "Numerical Investigation of Transonic Buffet on a Three-Dimensional Wing Using Incremental Mode Decomposition,” AIAA Paper 2017-1436, 2017. doi:10.2514/6.2017-1436.

[27] Iovnovich, M., and Raveh, D. E., "Numerical Study of Shock Buffet on Three-Dimensional Wings," AIAA Journal, Vol. 53, No. 2, 2015, pp. 449-463. doi:10.2514/1.j053201.

[28] Plante, F., Dandois, J., Sartor, F., and Laurendeau, E., "Study of Three-Dimensional Transonic Buffet on Swept Wings," AIAA Paper 2017-3903, 2017. doi:10.2514/6.2017-3903.

[29] Moss, G. F., and Murdin, P. M., “Two-Dimensional Low-Speed Tunnel Tests on the NACA 0012 Section Including Measurements Made During Pitching Oscillations at the Stall,” Tech. Rep. C.P. No. 1145, Aeronautical Research Council, 1971.

[30] Gregory, N., Quincey, V. G., O’Reilly, C. L., and Hall, D. J., "Progress Report on Observations of Three-Dimensional Flow Patterns Obtained during Stall Development on Aerofoils, and on the Problem of Measuring Two-Dimensional Characteristics," Tech. Rep. C.P. No. 1146, Aeronautical Research Council, 1971.

[31] Manolesos, M., and Voutsinas, S. G., "Geometrical Characterization of Stall Cells on Rectangular Wings: Geometrical Characterization of Stall Cells,” Wind Energy, Vol. 17, No. 9, 2013, pp. 1301-1314. doi:10.1002/we.1634.

[32] Manolesos, M., Papadakis, G., and Voutsinas, S. G., "Experimental and Computational Analysis of Stall Cells on Rectangular Wings: Experimental and CFD Analysis of Stall Cells," Wind Energy, Vol. 17, No. 6, 2014, pp. 939-955. doi:10.1002/we.1609.

[33] Winkelman, A. E., and Barlow, J. B., "Flowfield Model for a Rectangular Planform Wing beyond Stall," AIAA Journal, Vol. 18, No. 8, 1980, pp. 1006-1008. doi:10.2514/3.50846.

[34] Dell'Orso, H., and Amitay, M., "Parametric Investigation of Stall Cell Formation on a NACA 0015 Airfoil," AIAA Journal, 2018, pp. 1-13. doi:10.2514/1.J056850.

[35] Yon, S. A., and Katz, J., "Study of the Unsteady Flow Features on a Stalled Wing," AIAA Journal, Vol. 36, No. 3, 1998, pp. 305-312. doi:10.2514/2.372.

[36] Schewe, G., "Reynolds-Number Effects in Flow around More-or-Less Bluff Bodies," Journal of Wind Engineering and Industrial Aerodynamics, Vol. 89, No. 14-15, 2001, pp. 1267-1289. doi:10.1016/S0167-6105(01)00158-1.

[37] Broeren, A. P., and Bragg, M. B., "Spanwise Variation in the Unsteady Stalling Flowfields of Two-Dimensional Airfoil Models," AIAA Journal, Vol. 39, No. 9, 2001, pp. 1641-1651. doi:10.2514/2.1501.

[38] Bertagnolio, F., Sørensen, N. N., and Rasmussen, F., "New Insight Into the Flow Around a Wind Turbine Airfoil Section," Journal of Solar Energy Engineering, Vol. 127, No. 2, 2005, p. 214. doi:10.1115/1.1861927.

[39] Kamenetskiy, D. S., Bussoletti, J. E., Hilmes, C. L., Venkatakrishnan, V., Wigton, L. B., and Johnson, F. T., "Numerical Evidence of Multiple Solutions for the Reynolds-Averaged Navier-Stokes Equations," AIAA Journal, Vol. 52, No. 8, 2014, pp. 1686-1698. doi:10.2514/1.J052676.

[40] Manni, L., Nishino, T., and Delafin, P.-L., "Numerical Study of Airfoil Stall Cells Using a Very Wide Computational Domain," Computers \& Fluids, Vol. 140, 2016, pp. 260-269. doi:10.1016/j.compfluid.2016.09.023.

[41] Elimelech, Y., Arieli, R., and Iosilevskii, G., "The Three-Dimensional Transition Stages over the NACA-0009 Airfoil at Reynolds Numbers of Several Ten Thousand,” Physics of Fluids, Vol. 24, No. 2, 2012, p. 024104. doi:10.1063/1.3682377. 
[42] Gallay, S., and Laurendeau, E., "Nonlinear Generalized Lifting-Line Coupling Algorithms for Pre/Poststall Flows," AIAA Journal, Vol. 53, No. 7, 2015, pp. 1784-1792. doi:10.2514/1.j053530.

[43] Paul, R. C., and Gopalarathnam, A., "Iteration Schemes for Rapid Post-Stall Aerodynamic Prediction of Wings Using a Decambering Approach," International Journal for Numerical Methods in Fluids, Vol. 76, No. 4, 2014, pp. $199-222$. doi:10.1002/fld.3931.

[44] Spalart, P. R., "Prediction of Lift Cells for Stalling Wings by Lifting-Line Theory," AIAA Journal, Vol. 52, No. 8, 2014 , pp. 1817-1821. doi:10.2514/1.J053135.

[45] Gross, A., Fasel, H. F., and Gaster, M., “Criterion for Spanwise Spacing of Stall Cells,” AIAA Journal, Vol. 53, No. 1, 2015, pp. 272-274. doi:10.2514/1.J053347.

[46] Weihs, D., and Katz, J., "Cellular Patterns in Poststall Flow over Unswept Wings," AIAA Journal, Vol. 21, No. 12, 1983, pp. 1757-1759. doi:10.2514/3.8321.

[47] Crow, S. C., "Stability Theory for a Pair of Trailing Vortices," AIAA Journal, Vol. 8, No. 12, 1970, pp. $2172-2179$. doi:10.2514/3.6083.

[48] Rodríguez, D., and Theofilis, V., "On the Birth of Stall Cells on Airfoils," Theoretical and Computational Fluid Dynamics, Vol. 25, No. 1-4, 2011, pp. 105-117. doi:10.1007/s00162-010-0193-7. 